Check for updates

Cite this: RSC Adv., 2018, 8, 10764

\title{
Study on the degradation mechanism and pathway of benzene dye intermediate 4-methoxy-2- nitroaniline via multiple methods in Fenton oxidation process
}

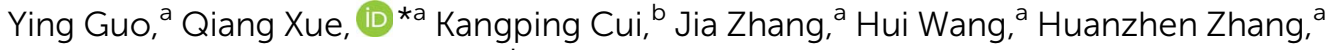 \\ Fang Yuan ${ }^{a}$ and Honghan Chen ${ }^{\star a}$
}

\begin{abstract}
Benzene dye intermediate (BDI) 4-methoxy-2-nitroaniline (4M2NA) wastewater has caused significant environmental concern due to its strong toxicity and potential carcinogenic effects. Reports concerning the degradation of 4M2NA by advanced oxidation process are limited. In this study, 4M2NA degradation by Fenton oxidation has been studied to obtain more insights into the reaction mechanism involved in the oxidation of 4M2NA. Results showed that when the 4M2NA (100 $\mathrm{mg} \mathrm{L}^{-1}$ ) was completely decomposed, the TOC removal efficiency was only $30.70-31.54 \%$, suggesting that some by-products highly recalcitrant to the Fenton oxidation were produced. UV-Vis spectra analysis based on Gauss peak fitting, HPLC analysis combined with two-dimensional correlation spectroscopy and GC-MS detection were carried out to clarify the degradation mechanism and pathway of 4M2NA. A total of nineteen reaction intermediates were identified and two possible degradation pathways were illustrated. Theoretical TOC calculated based on the concentration of oxalic acid, acetic acid, formic acid, and 4M2NA in the degradation process was nearly $94.41-97.11 \%$ of the measured TOC, indicating that the oxalic acid, acetic acid and formic acid were the main products. Finally, the predominant degradation pathway was proposed. These results could provide significant information to better understand the degradation mechanism of 4M2NA.
\end{abstract}

Received 21st January 2018

Accepted 11th March 2018

DOI: $10.1039 / c 8 r a 00627 j$

rsc.li/rsc-advances

\section{Introduction}

Benzene dye intermediates (BDIs) like 4-methoxy-2-nitroaniline (4M2NA) are important industrial chemicals and have a wide range of applications in the dye and pharmaceutical industries. Their production wastewater is often highly toxic, high in color, high in both substrate and salt concentrations, and does not degrade easily. ${ }^{1-3}$ Because of its highly toxic, carcinogenic, teratogenic and mutagenic hazards, ${ }^{4-6}$ BDI $4 \mathrm{M} 2 \mathrm{NA}$ has been listed as a priority pollutant in many countries. ${ }^{7}$ In recent years, due to the illegal discharge and leakage in the production process ${ }^{8}$ BDIs have been detected in many industrial parks and surrounding surface and underground water.9-11 According to the Pollution Events of Tengger Desert in China, ${ }^{12}$ a wide range of BDIs were detected with a concentration of up to 100$120 \mathrm{mg} \mathrm{L}^{-1}$ in both surface and underground water, which have

\footnotetext{
${ }^{a}$ Beijing Key Laboratory of Water Resources and Environmental Engineering, School of Water Resources and Environment, China University of Geosciences, Beijing 100083, China. E-mail: xueqiang@cugb.edu.cn; chenhh@cugb.edu.cn; Tel: +86-10-82322281; +86-10-82323345

${ }^{b}$ School of Resources and Environmental Engineering, Hefei University of Technology, Hefei 230009, China
}

threatened groundwater safety seriously. Therefore, it is greatly urgent to control the BDIs pollution in our environment. ${ }^{\mathbf{1 3 , 1 4}}$

In recent years, many methods, such as extraction, ${ }^{15,16}$ adsorption $^{17}$ and biodegradation, ${ }^{18,19}$ have been used to decompose the wastewater of BDIs. Because of its stable structure and strong toxicity, BDIs wastewater is difficult to be effectively treated by conventional physicochemical and biochemical effects. In addition, these technologies have some disadvantages. For example, the extraction chemicals are also very toxic and expensive. Adsorption method is not cost effective, not easy to be regenerated and only move the pollutants from the water phase to absorbents, which is not a complete treatment method. ${ }^{6,20}$ Biodegradation is usually slower and with less shock resistant. ${ }^{21}$ Therefore, it is necessary to find a more effective way to treat the wastewater of BDIs.

Due to the properties of anti-biodegradation, anti-oxidation and anti-photolysis of BDIs, ${ }^{22}$ advanced oxidation technology (AOT) seems a suitable and promising treatment method. ${ }^{23,24}$ This is based on their strong oxidation performance and a wide range of applications of AOT. ${ }^{25-29}$ For AOT, electrochemical incineration, ${ }^{30}$ microwave radiation, ${ }^{5}$ photocatalysis, ${ }^{31,32}$ and other Fenton methods ${ }^{2,4}$ have been also used to treat BDIs wastewater effectively. However, the above methods have some 
limitations in practical application. Such as photocatalysis, the absorption range of commonly used ultraviolet light is narrow. Some suspended matter and deep chroma in printing and dyeing wastewater will affect the photocatalytic effect, and the electron-hole pair is easy to be recombined and inactivated..$^{33}$ In contrast, Fenton advanced oxidation method has a great practical potential, due to its high efficiency, simple equipment, short reaction time, low additional energy and easy to operate, the Fenton oxidation process has been selected for the treatment of BDIs wastewater. ${ }^{34,35}$

During the Fenton reaction, the chain reaction between $\mathrm{Fe}^{2+}$ and $\mathrm{H}_{2} \mathrm{O}_{2}$ catalyzes the formation of hydroxyl radicals $\left({ }^{\circ} \mathrm{OH}\right)$ with strong oxidizing ability, ${ }^{36}$ which can oxidize many kinds of organic matters non-selectively and is especially good for the treatment of organic wastewater that is recalcitrant to biological treatment or general chemical oxidation. ${ }^{37,38}$

Therefore, in recent years, researchers have paid more attention to the use of various Fenton technologies for the treatment of BDIs, and study the mechanism and identify the degradation products. El-Ghenymy et al. $^{4}$ have studied the use of electro-Fenton and solar photoelectro-Fenton technology for the treatment of sulfanilic acid solutions, optimized the processing parameters, and identified the intermediate products. Masomboon et al. have compared the characteristics and kinetics of oxidation degradation of 2,6-dimethylaniline by Fenton, ${ }^{39}$ electro-Fenton ${ }^{\mathbf{4 0}}$ and photoelectro-Fenton process, ${ }^{\mathbf{4 1}}$ and discussed the reaction mechanism and possible degradation intermediates. Shen J. et $a .^{\mathbf{4 2}}$ studied the Fenton technology combined with zero valent iron reduction for the pretreatment 2,4-dinitroanisole and discussed the change of intermediate products in each reaction stage.

Although several studies have been conducted on the oxidation of Fenton to some of the BDIs, however, with the development of dye intermediates industry, more stable BDIs have been developed and applied. 4M2NA, as an important new benzene dye intermediate, has been widely used in the manufacture and synthesis of many organic dyes, drugs and sensitive materials in recent years. ${ }^{43}$ Compared to other BDIs, 4M2NA has electron donating group $\left(-\mathrm{NH}_{2}\right)$, electron withdrawing groups $\left(-\mathrm{NO}_{2}\right)$ and neutral groups $\left(-\mathrm{OCH}_{3}\right)$, and its structure is more complex. In addition, 4M2NA, a highly toxic substance, has potential mutagenic and carcinogenic effects and even can cause liver poisoning and hemolytic anemia. ${ }^{44}$ It has been listed as a priority pollutant in several countries. ${ }^{7}$

However, the researches at home and abroad are mostly focused on the synthesis, manufacture, physical properties ${ }^{\mathbf{4 3 , 4 5}}$ and toxicity tests ${ }^{44}$ of $4 \mathrm{M} 2 \mathrm{NA}$, but the studies mainly on the oxidative degradation by Fenton method have seldom been reported.

In recent years, the implementation goals of Fenton technology have shifted from the complete elimination of pollutants to the partial degradation of pollutants aiming at reducing toxicity of pollutants and improving the biodegradability of wastewater. Therefore, monitoring the reaction intermediates is also essential for understanding and predicting the biocompatibility of treated wastewater by Fenton method. ${ }^{\mathbf{4 6 , 4 7}}$ Hence, it is of great significance to understand the characteristics and mechanism of the degradation of 4M2NA by Fenton method.

In this study, 4M2NA was selected as the research target. Firstly, the effect of various factors (initial pH, initial $\mathrm{H}_{2} \mathrm{O}_{2}$ concentration, and initial $\mathrm{Fe}^{2+}$ concentration) on Fenton oxidative degradation of 4M2NA was analyzed. Then the mechanism and possible pathway of the 4M2NA degradation were predicted using UV-Vis spectra analysis based on Gauss peak fitting, HPLC measurement combined with twodimensional correlation spectroscopy and GC-MS analysis. Finally, based on the theoretical TOC calculation between 4M2NA and main reaction intermediates, the predominant degradation pathway was also proposed.

\section{Materials and methods}

\subsection{Chemicals and materials}

The 4M2NA (CAS: 96-96-8), with the purity of 99\%, was purchased from J\&K Scientific Ltd., The $\mathrm{NaOH}$, anhydrous $\mathrm{Na}_{2} \mathrm{SO}_{4}, \mathrm{FeSO}_{4} \cdot 7 \mathrm{H}_{2} \mathrm{O}, \mathrm{H}_{2} \mathrm{O}_{2}(30 \%)$, methanol, phosphoric acid, $\mathrm{KH}_{2} \mathrm{PO}_{4}, n$-hexane, formic acid, acetic acid and oxalic acid were received from Sinopharm Chemical Reagent Co., Ltd. The physical and chemical properties of 4M2NA are shown in Table 1.

\subsection{Experimental setup}

The 4M2NA wastewater sample $(500 \mathrm{~mL})$ was put in a beaker $(1 \mathrm{~L})$ with a magnetic stirrer. The initial solution $\mathrm{pH}$ was adjusted to

Table 1 Physical and chemical properties of 4M2NA

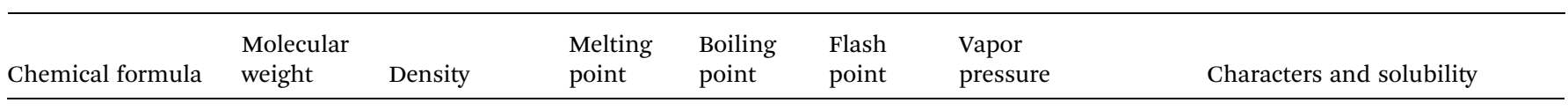

$\mathrm{C}_{7} \mathrm{H}_{8} \mathrm{~N}_{2} \mathrm{O}_{3}$

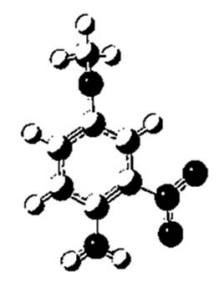

168.15 $1.318 \mathrm{~g} \mathrm{~cm}^{-3} \quad 124.0{ }^{\circ} \mathrm{C}$

$338.3{ }^{\circ} \mathrm{C}$

$158.4{ }^{\circ} \mathrm{C}$

$9.93 \times 10^{-5} \mathrm{mmHg}$

Orange red powder, soluble in water, ethanol, ether, slightly soluble in benzene 
the desired value by using $0.1 \mathrm{M} \mathrm{H}_{2} \mathrm{SO}_{4}$ or $0.1 \mathrm{M} \mathrm{NaOH}$ solution. A measured amount of catalytic $\mathrm{FeSO}_{4} \cdot 7 \mathrm{H}_{2} \mathrm{O}$ was added, followed by the addition of $\mathrm{H}_{2} \mathrm{O}_{2}$ into the solution to start the reaction. At selected time intervals $(1,5,10,30,60,90,120,180 \mathrm{~min}), 5 \mathrm{~mL}$ aliquots of the reaction mixture were taken and immediately injected with 1.0 or $0.1 \mathrm{M} \mathrm{NaOH}$ (or methanol, for the identification of organic products) to terminate the reaction. The mixed solution was centrifuged for $10 \mathrm{~min}$ at $12000 \mathrm{rpm}$, and the supernatant was withdrawn for the subsequent analysis.

All measurements were performed in triplicate, and the results displayed in tables were the average value of at least three measurements with an accuracy of $\pm 5 \%$.

\subsection{Chemical analysis}

The concentration of 4M2NA was measured by high performance liquid chromatography (HPLC, LC-20AT, SHIMADZU), equipped with a C18 analytical column $(5 \mu \mathrm{m}, 150 \mathrm{~mm} \times 4.6$ $\mathrm{mm}$ ) at $30{ }^{\circ} \mathrm{C}$. The mobile phase was methanol at a flow rate of

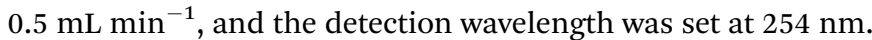
The injection volume was $10 \mu \mathrm{L}$. TOC was measured using a TOC analyzer (TOC-VWP, SHIMADZU). The residence time was 12 min. pH was determined by glass electrode method.

The oxidation products of 4M2NA were identified by GC-MS (Agilent 6890N/5975C) measurement. At selected time intervals, $15 \mathrm{~mL}$ reaction solution (with $5 \mathrm{~mL}$ methanol) was extracted with $10 \mathrm{~mL}$ hexane in triplicate. The organic phases were combined and dried by nitrogen gas at a gentle stream, and then dissolved in $1 \mathrm{~mL}$ hexane for GC-MS analysis. Organic phase was injected into the GC-MS for analysis after desiccation with anhydrous $\mathrm{Na}_{2} \mathrm{SO}_{4}$. The oxidation products were analyzed using the GC-MS with a HP-5MS chromatographic column $(60 \mathrm{~m} \times 0.25 \mathrm{~mm} \times 0.25 \mu \mathrm{m})$. The temperature programmed was that the initial temperature of $40{ }^{\circ} \mathrm{C}$ maintained for $7 \mathrm{~min}$ and post run at $150{ }^{\circ} \mathrm{C}$ maintained for $4 \mathrm{~min}$. The flow rate of the carrier gas (He) was $1.0 \mathrm{~mL} \mathrm{~min}^{-1}$ and the split ratio was $10: 1$. The temperature of the ion source was $230{ }^{\circ} \mathrm{C}$, respectively. The energy of the ion source was $70 \mathrm{eV}$. The full scan spectrum $(\mathrm{m} / z 25-500)$ was acquired and the solvent delay was set to $4 \mathrm{~min}$. Chromatograms were compared between the control and experimental groups to detect possible products.

Low molecular weight organic acids (LMWOAs) were measured by (HPLC, LC-20AT, SHIMADZU), equipped with an inert sustain swift-C18 analytical column $(5 \mu \mathrm{m}, 250 \mathrm{~mm} \times 4.6$ $\mathrm{mm}$ ) at $30^{\circ} \mathrm{C}$. The mobile phase was $\mathrm{KH}_{2} \mathrm{PO}_{4}$ solution (with $2 \%$ methanol) methanol at a flow rate of $0.8 \mathrm{~mL} \mathrm{~min}^{-1}$, and the detection wavelength was set at $210 \mathrm{~nm}$. The injection volume was $10 \mu \mathrm{L}$.

The UV-Vis spectras of 4M2NA samples were analyzed by using Gauss multi-peak fitting. ${ }^{48}$ The method is based on the description of each spectrum by a series of Gaussian peaks. ${ }^{\mathbf{9}}$ The HPLC spectra of a series of 4M2NA samples were analyzed by the method of two-dimensional correlation spectroscopy analysis described by Noda and Ozaki. ${ }^{50}$ The dynamic spectra that represent the variation of spectral intensity compared with the reference spectrum can be calculated from the following:

$$
\tilde{x}_{j}(v)=\tilde{x}\left(v, t_{j}\right)=x\left(v, t_{j}\right)-\bar{x}(v), j=1,2, \ldots, m,
$$

The variable $v$ is the spectral index of HPLC. $\tilde{x}\left(v, t_{j}\right)$ is the dynamic spectra measured at $m$ equally spaced points in perturbation $t$ between $t_{1}$ and $t_{m}$, and the average spectrum $\bar{x}(v)=\sum_{j=1}^{m} x\left(v, t_{j}\right) / m$ has been subtracted from raw data $x\left(v, t_{j}\right)$. The synchronous correlation intensity of two spectral indices can be directly calculated from the following:

$$
\Phi\left(v_{1}, v_{2}\right)=\frac{1}{m-1} \sum_{j=1}^{m} \tilde{x}_{j}\left(v_{1}\right) \tilde{x}_{j}\left(v_{2}\right)
$$

Synchronous correlation spectrum $\Phi\left(v_{1}, v_{2}\right)$ represents synchronous changes of two spectral intensities measured at $v_{1}$ and $v_{2}$. A positive $\Phi\left(v_{1}, v_{2}\right)$ indicates that the spectral intensities at $v_{1}$ and $v_{2}$ are either increasing or decreasing simultaneously. A negative value indicates that one of the spectral intensities is increasing while the other is decreasing. ${ }^{51}$ The two-dimensional correlation spectroscopy analysis was produced using 2Dshige software (Kwansei-Gakuin University, Japan).

\section{Results and discussion}

\subsection{Degradation of 4M2NA}

In this study, experiments were carried out to investigate the $\mathrm{pH}$ and operational variables that could affect the 4M2NA degradation efficiency for the preparation of suitable reaction conditions. ${ }^{52}$

3.1.1 Effect of initial $\mathbf{p H}$. The effect of $\mathrm{pH}$ on the $4 \mathrm{M} 2 \mathrm{NA}$ degradation is illustrated in Fig. 1. As can be seen from Fig. 1(a), at the initial one min of the reaction, the degradation efficiency of $4 \mathrm{M} 2 \mathrm{NA}$ in each group reached about $40 \%$, but there were still differences under different $\mathrm{pH}$ conditions. When $\mathrm{pH}$ was 2.0, the overall reaction rate was lower than that of the other groups, and the apparent rate constant was only $0.0068 \mathrm{~s}^{-1}$. However, when $\mathrm{pH}$ was in the range of 3.0-7.0, the rate of reaction decreased slightly with an increase of $\mathrm{pH}$. The rate constant $\left(0.0276 \mathrm{~s}^{-1}\right)$ was highest at $\mathrm{pH}$ of 3.0. And when the reaction was carried out at $180 \mathrm{~min}$, the removal efficiency of 4M2NA could reach more than $98 \%$.

On the other hand, as shown in Fig. 1(b), when pH was 2.0, the TOC removal efficiency was only $7.66 \%$, but the TOC removal efficiency (16.88\%) was the highest at $\mathrm{pH}$ of 3.0. When $\mathrm{pH}$ was increased from 3.0 to 7.0, the removal efficiency of TOC was slightly decreased, but they were basically maintained at around $13.0-16.0 \%$. In summary, the degradation of $4 \mathrm{M} 2 \mathrm{NA}$ by Fenton oxidation can be carried out at a wide $\mathrm{pH}$ range.

For analysis, when the solution $\mathrm{pH}$ was lower $(\mathrm{pH}=2.0)$, the high concentration of $\mathrm{H}^{+}$reacted with ${ }^{\circ} \mathrm{OH}$ and reduced the amount of ${ }^{\circ} \mathrm{OH}$ production, thus affecting the overall efficiency of the reaction..$^{53}$ Besides, the formation of the complex species $\left[\mathrm{Fe}\left(\mathrm{H}_{2} \mathrm{O}\right)_{6}\right]^{2+}$ slows down the oxidation reaction due to its slower reaction with $\mathrm{H}_{2} \mathrm{O}_{2}$ compared to that of $\left[\mathrm{Fe}(\mathrm{OH})\left(\mathrm{H}_{2} \mathrm{O}\right)_{5}\right]^{+}$. The formation of the stable oxonium ion $\left[\mathrm{H}_{3} \mathrm{O}_{2}\right]^{+}$in the presence of 

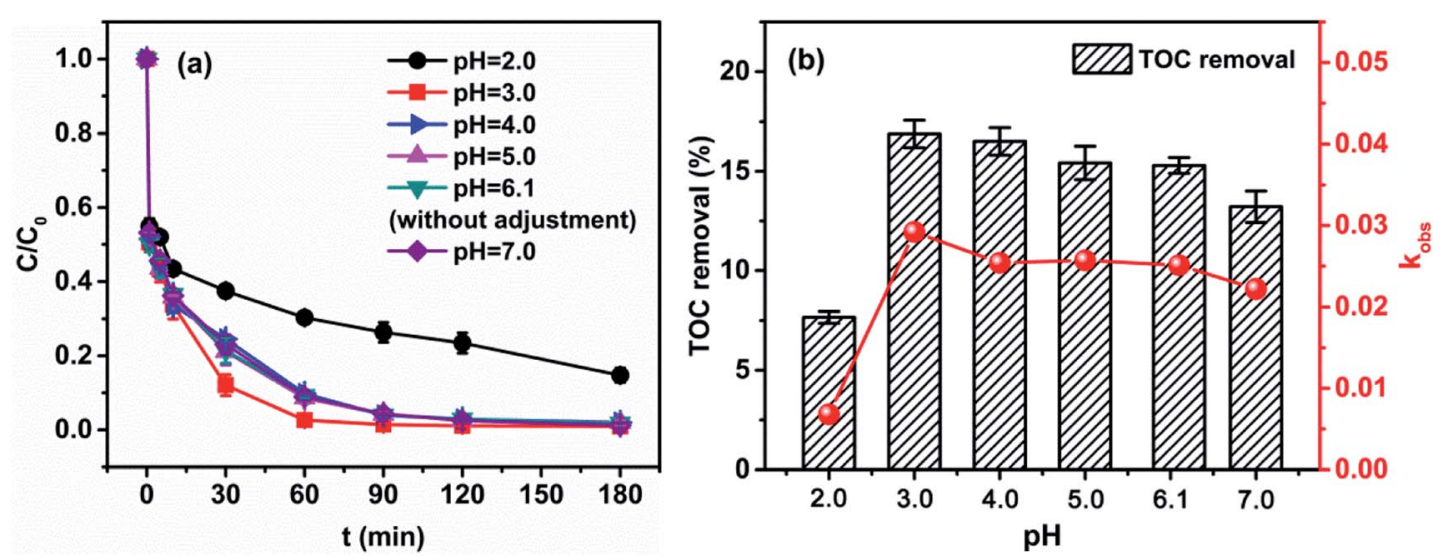

Fig. 1 Effect of initial $\mathrm{pH}$ on (a) degradation of $4 \mathrm{M} 2 \mathrm{NA}$ and (b) TOC removal and $k_{\mathrm{obs}}\left([4 \mathrm{M} 2 \mathrm{NA}]_{0}=100 \mathrm{mg} \mathrm{L}^{-1},\left[\mathrm{H}_{2} \mathrm{O}_{2}\right]_{0}=2 \mathrm{mM}\left[\mathrm{Fe}^{2+}\right]_{0}=0.4 \mathrm{mM}\right.$, and temperature $=25^{\circ} \mathrm{C}$; the $\mathrm{pH}$ without adjustment was about $6.12 \pm 0.01$ ).

high concentrations of $\mathrm{H}^{+}$also makes the peroxide electrophilic enhancing its stability and presumably hindering the reaction activity between $\mathrm{H}_{2} \mathrm{O}_{2}$ and $\mathrm{Fe}^{2+}{ }^{24,55}$ On the contrary, generally under the conditions of near neutral $\mathrm{pH}$, the production of ${ }^{\circ} \mathrm{OH}$ is inhibited by ferric hydroxo complexes. Moreover, $\mathrm{Fe}^{2+} \mathrm{or} \mathrm{Fe}^{3+}$ tends to generate a variety of amorphous complex precipitation, ${ }^{56}$ which significantly decreases the oxidation capability of the system. However, the degradation efficiency was generally good, when the $\mathrm{pH}$ was in the range of 3.0-7.0 in our current study. It was probably due to the formation of LMWOAs in the reaction process, ${ }^{57}$ so that the solution $\mathrm{pH}$ can be reduced rapidly to about 3.0 when the initial pH near neutral condition, and the treatment efficiency is not greatly affected.

Based on the above results, the degradation of 4M2NA by Fenton method was feasible and efficient at an initial pH of near neutral condition. Therefore, subsequent experiments were performed under unadjusted $\mathrm{pH}(6.12 \pm 0.01)$ condition.

3.1.2 Effect of initial $\mathrm{H}_{2} \mathrm{O}_{2}$ concentration. Generally, it has been accepted that the degradation efficiency of an organic contaminant increases with an increase of the concentration of $\mathrm{H}_{2} \mathrm{O}_{2}$. However, in the actual wastewater treatment process, large initial $\mathrm{H}_{2} \mathrm{O}_{2}$ dosage may affect the treatment efficiency, due to the formation of large amount of oxygen bubbles, thereby wasting a large number of ${ }^{\circ} \mathrm{OH}$. Therefore, it is very important to determine the most suitable dosage of $\mathrm{H}_{2} \mathrm{O}_{2}$. The effect of initial $\mathrm{H}_{2} \mathrm{O}_{2}$ concentration on the 4M2NA degradation is illustrated in Fig. 2.

In this study, the degradation effect of 4M2NA by Fenton method was gradually increased with an increase of initial $\mathrm{H}_{2} \mathrm{O}_{2}$ concentration. Besides, it could be seen from Fig. 2(a) that the degradation efficiency of 4M2NA did not decrease significantly when the concentration of $\mathrm{H}_{2} \mathrm{O}_{2}$ was too high. However, from Fig. 2(b), the reaction rate and overall TOC removal efficiency increased greatly with an increase the initial $\mathrm{H}_{2} \mathrm{O}_{2}$ concentration (from 1.0 to $4.0 \mathrm{mM}$ ), and the increase rate became slow when the initial concentration of $\mathrm{H}_{2} \mathrm{O}_{2}$ increased from 4.0 to $10.0 \mathrm{mM}$. The apparent rate constant $k_{\mathrm{obs}}$ showed a similar trend. However, if according to the ratio of the TOC removal and initial $\mathrm{H}_{2} \mathrm{O}_{2}$ concentration to calculate effective utilization coefficient of $\mathrm{H}_{2} \mathrm{O}_{2}$, it could be found that with an increase of initial $\mathrm{H}_{2} \mathrm{O}_{2}$ concentration, the effective utilization coefficient of $\mathrm{H}_{2} \mathrm{O}_{2}$ was stable from 1.0 to $4.0 \mathrm{mM}$ but decreased substantially from 4.0 to $10.0 \mathrm{mM}$. The maximum effective utilization coefficient of 0.3785 was observed at the initial $\mathrm{H}_{2} \mathrm{O}_{2}$ concentration
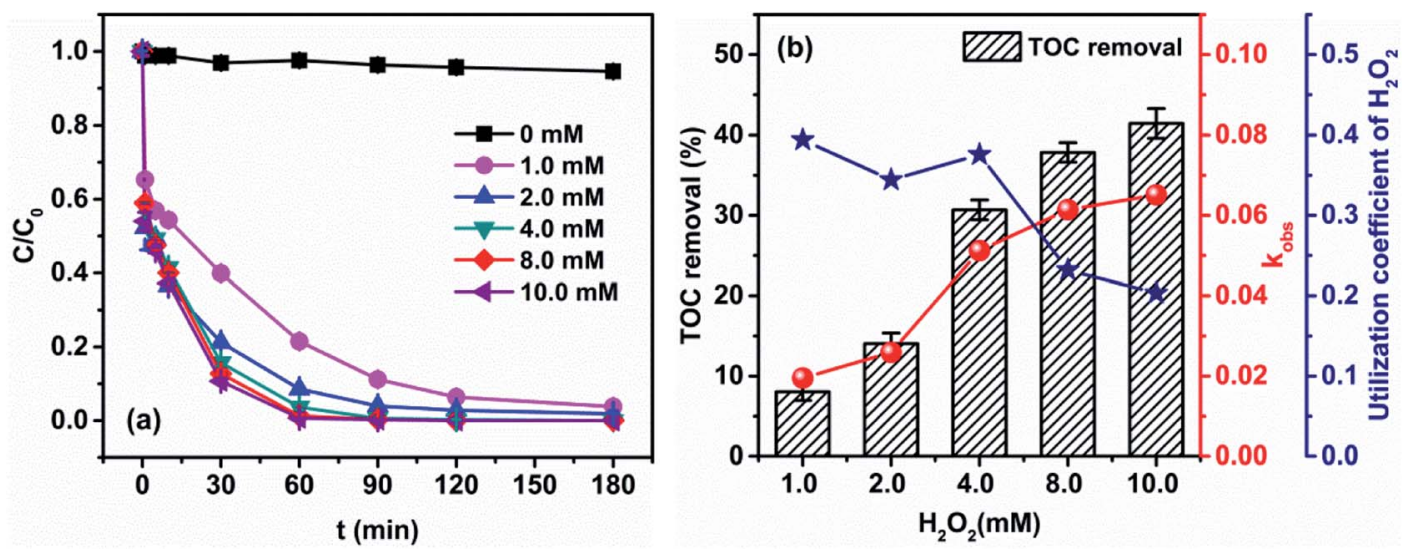

Fig. 2 Effect of initial $\mathrm{H}_{2} \mathrm{O}_{2}$ concentration on (a) degradation of $4 \mathrm{M} 2 \mathrm{NA}$ and (b) TOC removal and $k_{\mathrm{obs}}\left([4 \mathrm{M} 2 \mathrm{NA}]_{0}=100 \mathrm{mg} \mathrm{L}{ }^{-1}\right.$, $\left[\mathrm{Fe}^{2+}\right]_{0}=$ $0.4 \mathrm{mM}$, and temperature $=25^{\circ} \mathrm{C} ; \mathrm{pH}=6.12 \pm 0.01$ ). 
of $4.0 \mathrm{mM}$. This is because too much $\mathrm{H}_{2} \mathrm{O}_{2}$ generated large amounts of oxygen, which reduce the efficiency of effective utilization of $\mathrm{H}_{2} \mathrm{O}_{2} \cdot{ }^{39}$

Therefore, considering the above factors, the most suitable initial concentration of $\mathrm{H}_{2} \mathrm{O}_{2}$ was $4.0 \mathrm{mM}$, simultaneously the TOC removal efficiency and the apparent rate constant were $30.70 \%$ and $0.0512 \mathrm{~s}^{-1}$, respectively.

3.1.3 Effect of initial $\mathrm{Fe}^{2+}$ concentration. Experiments were performed as the $\mathrm{Fe}^{2+}$ initial concentration ranged from 0.1 to 1.0 mM. The results are shown in Fig. 3.

The results showed that the degradation of 4M2NA by Fenton oxidation was enhanced significantly with an increase of initial concentration of $\mathrm{Fe}^{2+}$. The apparent rate constant increased exponentially from 0.0009 to $0.1674 \mathrm{~s}^{-1}$ when the initial $\mathrm{Fe}^{2+}$ concentration ranged from 0.1 to $1.0 \mathrm{mM}$. And when the initial $\mathrm{Fe}^{2+}$ concentration was larger than or equal to $0.4 \mathrm{mM}$, the removal efficiency of $4 \mathrm{M} 2 \mathrm{NA}$ could reach $100 \%$ after $180 \mathrm{~min}$. But the TOC removal efficiency initially increased then decreased. When the initial concentration of $\mathrm{Fe}^{2+}$ increased from 0.1 to $0.4 \mathrm{mM}$, the TOC removal efficiency increased from $3.26 \%$ to $31.54 \%$, reaching the maximum value. However, when the initial concentration of $\mathrm{Fe}^{2+}$ continued to increase up to $1.0 \mathrm{mM}$, the TOC removal efficiency gradually decreased to $22.95 \%$.

$\mathrm{Fe}^{2+}$ is the catalyst in Fenton oxidation reaction. With an increase of initial $\mathrm{Fe}^{2+}$ concentration, $\mathrm{H}_{2} \mathrm{O}_{2}$ could be catalyzed to produce more ${ }^{\circ} \mathrm{OH}$, which could degrade $4 \mathrm{M} 2 \mathrm{NA}$ effectively. However, when the initial concentration of $\mathrm{Fe}^{2+}$ increased to a certain level, the TOC removal efficiency was still minor although the removal of 4M2NA was quite significant, which was probably because 4M2NA produced more refractory intermediates. On the other hand, excessive $\mathrm{Fe}^{2+}$ react with ${ }^{\circ} \mathrm{OH}$ to cause the depletion of ${ }^{\circ} \mathrm{OH}\left({ }^{\circ} \mathrm{OH}+\mathrm{Fe}^{2+} \rightarrow \mathrm{Fe}^{3+}+\mathrm{OH}^{-}\right)$, thereby reducing the degradation efficiency of organic constituents in the whole system. Therefore, a suitable initial concentration of $\mathrm{Fe}^{2+}$ was $0.4 \mathrm{mM}$.

The above results revealed that when the $4 \mathrm{M} 2 \mathrm{NA}$ degradation was quite complete, it seemed the apparent removal for total TOC did not occur, which was a sign that some organic substances highly recalcitrant to the Fenton process had been formed $^{58}$ (the analysis of intermediates formed was discussed in detail below).

\subsection{Oxidation products and proposed pathways}

The oxidative degradation of 4M2NA using Fenton reagent by producing ${ }^{\circ} \mathrm{OH}$ was a complex chemical reaction process. The ${ }^{\circ} \mathrm{OH}$ increases or terminates the reaction chain by means of hydrogen abstraction, addition, fragmentation, etc. Because of the high activity of $\mathrm{OH}$, the reaction is usually fast with low activation energy, and several reaction pathways can occur simultaneously, thus producing complex chemical products. In this study, we used UV-Vis, HPLC, and GC-MS methods to characterize the variation of the products during the degradation of 4M2NA. Based on the results in 3.1 Section, the reaction conditions were set as follows: $[4 \mathrm{M} 2 \mathrm{NA}]_{0}=100 \mathrm{mg} \mathrm{L}{ }^{-1},\left[\mathrm{H}_{2} \mathrm{O}_{2}\right]_{0}$ $=4.0 \mathrm{mM},\left[\mathrm{Fe}^{2+}\right]_{0}=0.4 \mathrm{mM}, \mathrm{pH}=6.12 \pm 0.01$, temperature $=$ $25{ }^{\circ} \mathrm{C}$.

3.2.1 UV-Vis. In order to explain the structural characteristics of intermediates, UV-Vis analysis was carried out for samples taken at different time periods. And the UV-Vis spectra obtained at different reaction time (0, 1, 30, 90 and $180 \mathrm{~min})$ were analyzed by Gauss peak fitting. The possible structures and their changes were also analyzed, as shown in Fig. 4.

Fig. 4(a) showed full wavelength UV-Vis absorption spectra of 4M2NA proceeded Fenton reaction. Wiff chromophore theory can be used to explain the relationship between the chromospheres behavior of most dyes and their intermediates and chromospheres. ${ }^{59}$ For the dye intermediate 4M2NA, the chromosphere is benzene ring, the chromophore is $-\mathrm{NO}_{2}$, and the chromophore bodies are $-\mathrm{NH}_{2}$ and $-\mathrm{OCH}_{3}$. Through the Gauss peak fitting (Fig. 4(b)), it could be seen clearly that the absorption peaks of the ultraviolet region at 230, 258 and $285 \mathrm{~nm}$ were characteristic peaks of benzene ring, $-\mathrm{NH}_{2}$ and $-\mathrm{OCH}_{3}$, respectively. ${ }^{6}$ The absorption peak at $450 \mathrm{~nm}$ corresponded to the $-\mathrm{NO}_{2}$ chromophore, produced by $\mathrm{n} \rightarrow \pi^{*}$ transition, namely, the visible chromophore.

The experimental results showed that with an increase of processing time, the peak intensities at 450, 230, 258 and
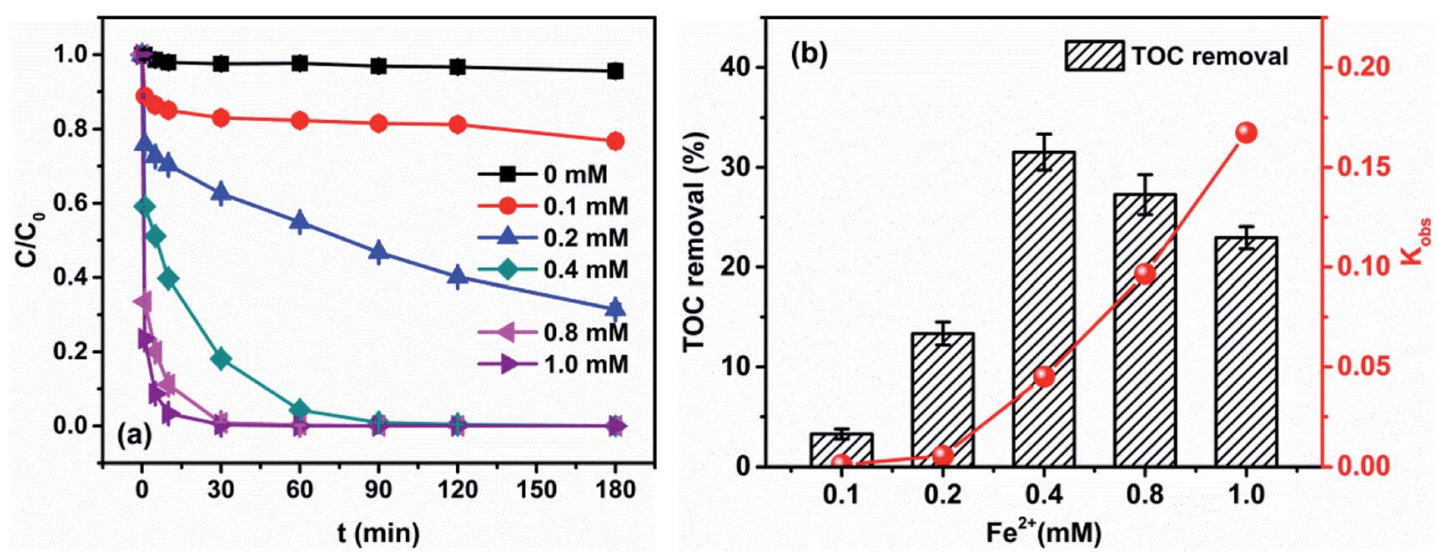

Fig. 3 Effect of initial Fe ${ }^{2+}$ concentration on (a) degradation of $4 \mathrm{M} 2 \mathrm{NA}$ and (b) TOC removal and $k_{\mathrm{obs}}\left(\left[4 \mathrm{M}_{2} \mathrm{NA}_{0}=100 \mathrm{mg} \mathrm{L}{ }^{-1}\right.\right.$, $\left[\mathrm{H}_{2} \mathrm{O}_{2}\right]_{0}=4 \mathrm{mM}$, and temperature $=25^{\circ} \mathrm{C} ; \mathrm{pH}=6.12 \pm 0.01$ ). 

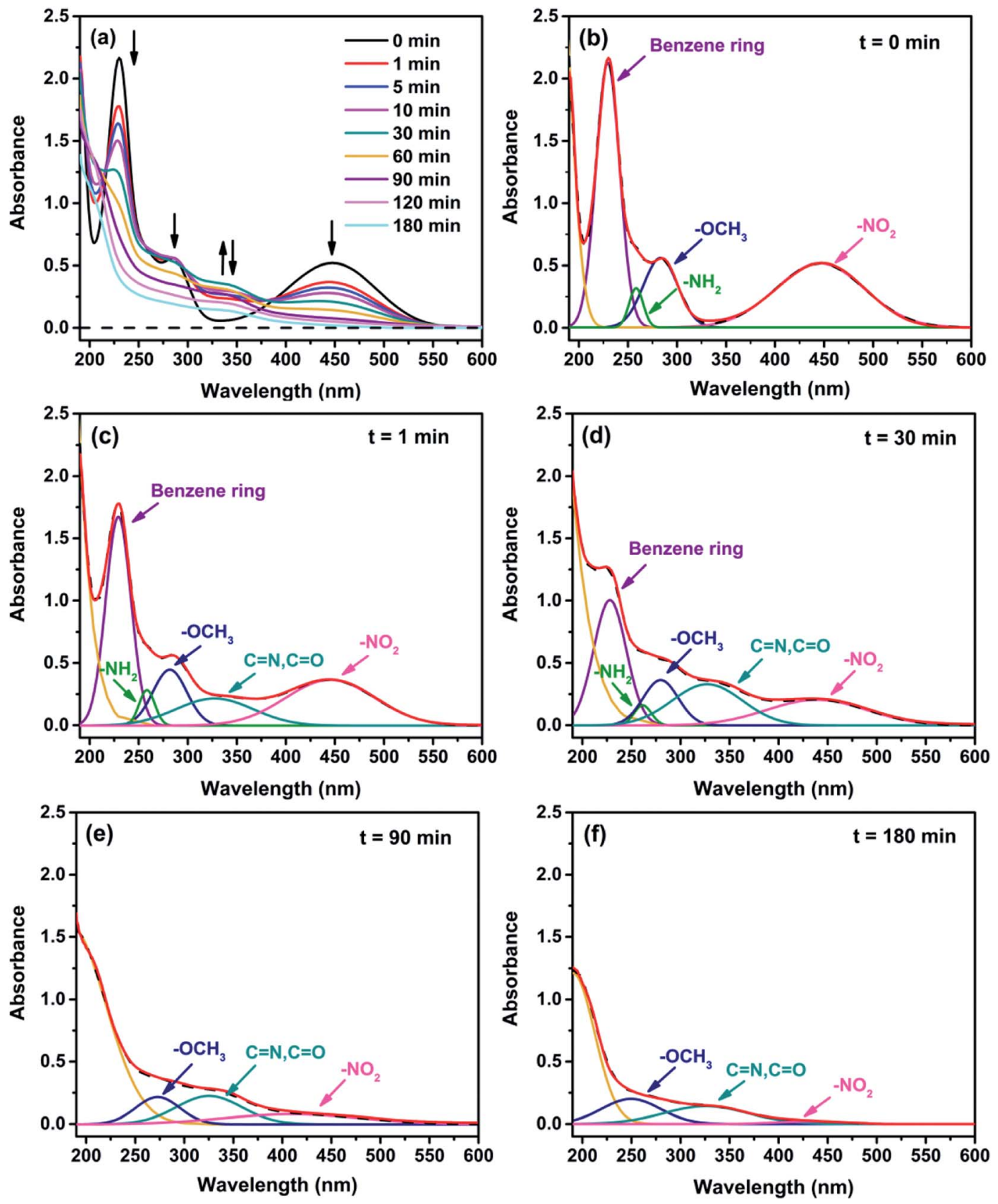

Fig. 4 Evolution of UV-Vis spectrum of 4M2NA during Fenton process (Gauss peak fitting).

$285 \mathrm{~nm}$ in the visible region were gradually weakened, i.e., the $-\mathrm{NO}_{2}$, benzene ring, $-\mathrm{NH}_{2}$ and $-\mathrm{OCH}_{3}$ were gradually destroyed. However, when the reaction time was $1 \mathrm{~min}$, a new absorption peak appeared at $326 \mathrm{~nm}$ in the ultraviolet region. The absorption peak was mainly expressed as $\mathrm{C}=\mathrm{O}$ or $\mathrm{C}=\mathrm{N}$ bond, indicating the possibility of producing ketones or acids. ${ }^{6}$ When the reaction time increased from 0 to $30 \mathrm{~min}$, the intensity of absorption peak gradually increased, then it decreased step by step when the reaction proceeded from 30 to $180 \mathrm{~min}$.

The TOC removal efficiency was approximately $30 \%$ after the reaction, indicating that there were still a great amount of intermediate products in the solution. In order to illustrate the degradation process more accurately, more analytic methods should be carried out for further understanding of the reaction mechanism.

3.2.2 HPLC. In order to further clarify the degradation mechanism of 4M2NA in Fenton process, the analysis of HPLC and two-dimensional correlation spectroscopy of retained peaks was carried out, as shown in Fig. 5.

Fig. 5(a) showed the retention peaks of solution in the chromatographic column at different reaction times after Fenton oxidation. The $X$ axis indicated the retention time, and the $Y$ axis indicated response sensitivity. The peak at retention time of 9.623 min was the characteristic peak of $4 \mathrm{M} 2 \mathrm{NA}$, and the peak 

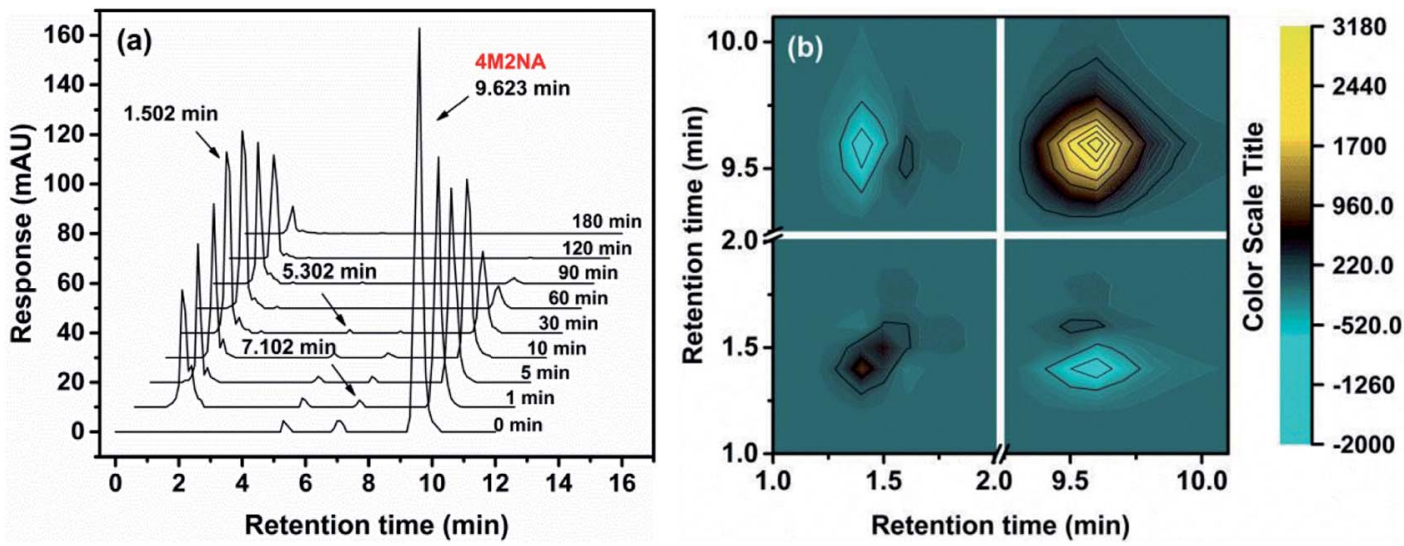

Fig. 5 HPLC spectrum (a) and two-dimensional correlation spectroscopy (b) in the process of degradation of 4M2NA by Fenton oxidation.

area gradually decreased with the reaction time prolonged, indicating that the 4M2NA molecule was fully degraded in a relatively short time (less than $1 \mathrm{~h}$ ), which was consistent with the result achieved by UV-Vis spectrum measurement. Among them, the characteristic peaks at retention time of 5.302 and $7.102 \mathrm{~min}$ indicated the trace impurities in the original sample, namely, 5-methoxybenzofurazan (CAS: 4413-48-3) and 3-nitroanisole (CAS: 555-03-3), which were also decayed as the reaction proceeded. When the reaction was carried out at $1 \mathrm{~min}$, three new characteristic peaks appeared at 1.502, 1.801 and $1.921 \mathrm{~min}$, and the peak intensity at $1.502 \mathrm{~min}$ was higher than those at both 1.801 and $1.921 \mathrm{~min}$. This was probably because 4M2NA was rapidly oxidized by ${ }^{\circ} \mathrm{OH}$ to produce phenols and the 'OH capture hydrogen from phenol, causing it open the ring to form the short chain carboxylic acids. As the reaction continued, the area of the peak at 1.502 min initially increased and then decreased. While, the peak areas at both 1.801 and 1.921 min decreased gradually.

The two-dimensional correlation spectroscopy method was used to further analyze the spectrum data of HPLC. The synchronous maps generated from the HPLC spectra during the whole oxidation process are shown in Fig. $5(\mathrm{~b})$. The sequential relationship of the main peaks was obtained through the comparison of the signs (positive or negative) from synchronous maps (upper-left corner). As mentioned above, a positive sign $\Phi\left(v_{1}, v_{2}\right)$ indicates that the spectral intensities at $v_{1}$ and $v_{2}$ are either increasing or decreasing simultaneously. A negative value indicates that one of the spectral intensities is increasing, while the other is decreasing. ${ }^{51}$ As can be seen, the comparison of the signs at upper-left corner of Fig. 5(b) was negative. Therefore, the change of 4M2NA peak area showed the opposite trend with that of the three unknown peaks, which indicated that some other products were produced during the process of the 4M2NA oxidative degradation.

Since the degradation process of BDIs by Fenton method was complex, it was difficult to infer the detailed degradation products of 4M2NA only on the basis of the retention peaks of HPLC.

According to previous studies, it was speculated that the peaks at retention time of 1.502 min were probably the short chain carboxylic acid produced by the opening of the benzene ring. Because such organic acids were linked to hydroxyl groups, carboxyl groups and other polar functional groups, and the retention time in the chromatographic column always short. ${ }^{59}$

It should be noted that this HPLC operating conditions were only suitable for relatively weaker polar organic molecules. For the main components of TOC in the later stage of the reaction, further analysis should be carried out by targeted methods such as GC-MS.

3.2.3 GC-MS. The 4M2NA produced a variety of intermediate products during the Fenton oxidation process. In order to identify the structures of intermediates, GC-MS analyses of samples at different time intervals $(0,1,5,30,60,90$ and 180 min) were carried out. The mass spectra corresponding to the larger peaks at the total ion flow were analyzed, and their similarity was evaluated by computer. Finally, the possible composition structure was obtained as shown in Table 2.

According to the total ion flow diagram of the standard dye sample at $0 \mathrm{~min}$, the peak at retention time of $17.455 \mathrm{~min}$ indicated 4M2NA, and the remaining peaks were dominated by column loss and indicated some trace impurities such as 5-methoxy-2,1,3-benzoxadiazole (CAS: 4413-48-3) and 1-methoxy3-nitrobenzene (CAS: 555-03-3). As the reaction proceeded, more small peaks appeared after 1 min reaction, mainly including newly generated 5-methoxy-2,1,3-benzoxadiazole (CAS: 4413-483), 1-methoxy-3-nitrobenzene (CAS: 555-03-3) and 4-methoxy-2nitrophenol (CAS: 1568-70-3). At the same time, some new peaks were formed, mainly including 4-methoxy-1,2-benzenediol (CAS: 3934-97-2), 4-methoxy-1,2-benzoquinone (CAS: 69818-23-1), toluene (CAS: 108-88-3). When the reaction proceeded to $5 \mathrm{~min}$, the above substances were still present and other new peaks were formed including $(2 E, 4 Z) 3$-methoxy-2,4-hexadienedinitrile (CAS: 1789-46-4), 3-butenamide (CAS: 432491-67-3), methacrylamide (CAS: 79-39-0), acrylamide (CAS: 79-06-1), 3-hexanone (CAS: 58938-8), 2-methyl-3-pentanone (CAS: 565-69-5), ethyl cyanate (CAS: 627-48-5), cyanoacetic acid (CAS: 372-09-8), acetic acid (CAS: 6419-7), acetaldehyde (CAS: 75-07-0) and hydrogen azide (CAS: 778279-8). After $30 \mathrm{~min}$ of reaction, the peaks above gradually disappeared. However, there were still several small peaks. Further 
Table 2 Intermediate products detected from TIC by GC-MS

\section{Compound name}

2-Methyl-3-pentanone

Methacrylamide

4.140

4.381

Toluene

Ethyl cyanate

Acrylamide

Hydrogen azide

3-Hexanone

4-Methoxy-1,2-benzenediol

4-Methoxy-1,2-benzoquinone

4.119

4.574

4.580

4.638

5.173

7.645
Retention time/min

Acetaldehyde

9.671

Acetic acid

5-Methoxy-2,1,3-benzoxadiazole

1-Methoxy-3-nitrobenzene
13.408

13.441
CAS number

Molecular structure

565-69-5

79-39-0

108-88-3

627-48-5

79-06-1

7782-79-8

589-38-8

3934-97-2

69818-23-1<smiles>CCOC#N</smiles><smiles>C=CC(N)=O</smiles>

$\mathbf{N} \equiv \mathbf{N}=\mathbf{N H}$

$\mathrm{CH}_{3}$<smiles>CCC(=O)CC</smiles>

$\mathrm{H}_{3} \mathrm{C}$<smiles>COc1ccc(O)c(O)c1</smiles>

$\mathrm{H}_{3} \mathrm{C}_{\mathrm{O}}$<smiles>COC1=CC(=O)C(=O)C=C1</smiles>

75-07-0<smiles>CC=O</smiles><smiles>C=C(C)C</smiles>

64-19-7

4413-48-3<smiles>COc1ccc2nonc2c1</smiles><smiles>COc1cccc([N+](=O)[O-])c1</smiles> 
Table 2 (Contd.)

\begin{tabular}{|c|c|c|c|}
\hline Compound name & Retention time/min & CAS number & Molecular structure \\
\hline$(2 E, 4 Z) 3$-Methoxy-2,4-hexadienedinitrile & 13.563 & $1789-46-4$ & \\
\hline Cyanoacetic acid & 15.549 & $372-09-8$ & \\
\hline 4-Methoxy-2-nitrophenol & 17.193 & $1568-70-3$ & \\
\hline 4-Methoxy-2-nitroaniline & 17.455 & $96-96-8$ & \\
\hline 3-Butenamide & 18.360 & $432491-67-3$ & \\
\hline
\end{tabular}

identification by HPLC showed that the final products were mainly oxalic acid (CAS: 144-62-7), formic acid (CAS: 64-18-6) and other substances.

3.2.4 Proposed degradation pathways of 4M2NA. According to the identification results of intermediate products by UVVis, HPLC and GC-MS measurements and the information in Table 2, the possible degradation pathway of 4M2NA in Fenton process could be shown in Fig. 6. There were two possible pathways for the degradation of $4 \mathrm{M} 2 \mathrm{NA}$ by Fenton oxidation.

From Fig. 6, for the major pathway (red box), at the beginning of the reaction, 4M2NA was oxidized to 2-nitro-4methoxyphenol. Because of the highest density of electron clouds near the $-\mathrm{NH}_{2}$ of the three substituents on $4 \mathrm{M} 2 \mathrm{NA},{ }^{\circ} \mathrm{OH}$ attacked $-\mathrm{NH}_{2}$ first, and $-\mathrm{NH}_{2}$ was oxidized to form hydroxyl $(-\mathrm{OH})$. At the same time, 4M2NA might also undergo deamination to produce 1-methoxy-3-nitrobenzene, which was then attacked by ${ }^{\circ} \mathrm{OH}$ and a hydroxyl substitution reaction occurred to produce 2-nitro-4-methoxyphenol. Because if there is an ortho- and para-position orienting group $\left(-\mathrm{OCH}_{3}\right)$ and an interposition orienting group $\left(-\mathrm{NO}_{2}\right)$ on the benzene ring, the position of the third substituent is determined mainly by the orthoand para-position orienting group, namely $-\mathrm{OCH}_{3}$. Therefore, the generation of 2-nitro-4-methoxyphenol from 1-methoxy-3nitrobenzene was possible and reasonable. The presence of $-\mathrm{OH}$ in benzene ring enhanced its activity. As the reaction continued, the $-\mathrm{NO}_{2}$ on the benzene ring was attacked by ${ }^{\circ} \mathrm{OH}$, and then the substitution reaction took place to form polyphenols $^{60}$ such as 4-methoxy-1,2-benzenediol, which might react with $\mathrm{Fe}^{3+}$ to produce $\mathrm{Fe}^{2+}$ and 4-methoxy-1,2-benzoquinone. ${ }^{61}$ However, 4-methoxy-1,2-benzoquinone was unstable. When it was further attacked by ${ }^{\circ} \mathrm{OH}$, the benzene ring was oxidized to fracture to form oxalic acid, acetaldehyde and other substances, ${ }^{62}$ which continued to be oxidized to form acetic acid, formic acid, etc., and eventually were mineralized to carbon dioxide, water and so on.

On the other hand, there may be another way. 5-Methoxy2,1,3-benzoxadiazole and 1-methoxy-3-nitrobenzene were detected at the early stage of reaction. Although these impurities contained in the original 4M2NA sample, the peak area varied with the reaction. So it was possible to combine $-\mathrm{NO}_{2}$ with $-\mathrm{NH}_{2}$ on the 4M2NA molecule to produce 5-methoxy-2,1,3benzoxadiazole in the early intense oxidizing atmosphere. Moreover, 4M2NA is usually used as an raw material for the manufacture of 5-methoxy-2,1,3-benzoxadiazole. Therefore, the result was reasonable. As the reaction continued, $(2 E, 4 Z) 3$ methoxy-2,4-hexadienedinitrile, ethyl cyanate and hydrogen azide were identified mainly due to the attack by ${ }^{\circ} \mathrm{OH}$ on the $\mathrm{C}=\mathrm{N}$ bond and the benzene ring, resulting in that the ring of 5methoxy-2,1,3-benzoxadiazole was broken. Meanwhile, the detected cyanoacetic acid, ethyl cyanate, hydrogen azide, 3butenamide, methacrylamide, acrylamide might be the 


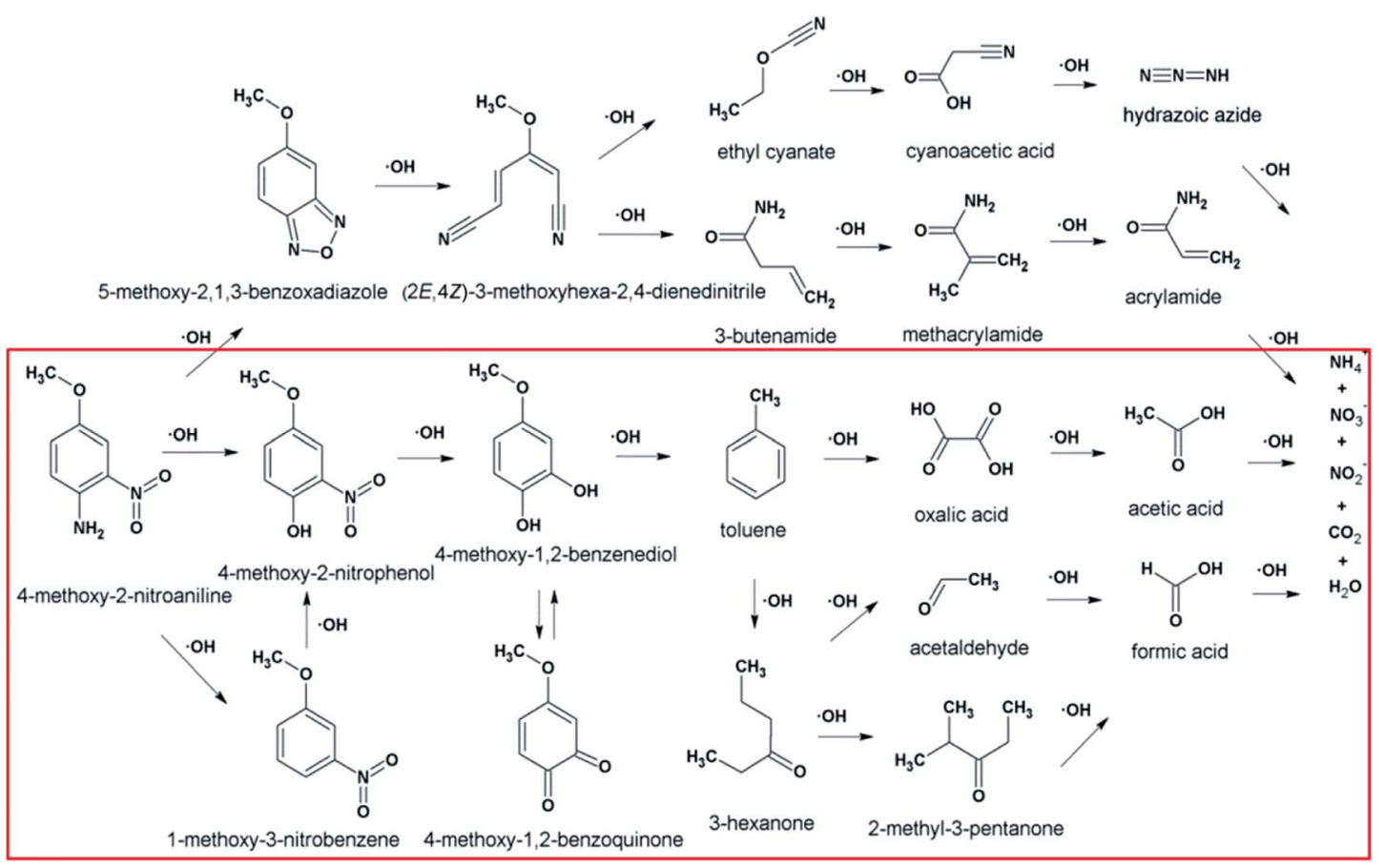

Fig. 6 Proposed degradation pathway of 4M2NA by Fenton method.

products of $(2 E, 4 Z) 3$-methoxy-2,4-hexadienedinitrile after ${ }^{\circ} \mathrm{OH}$ attack. They might eventually continue to be fully mineralized.

In summary, since the Fenton reaction is rapid and complex, the above reactions may occur simultaneously. Subsequent oxidation of these intermediate by-products yielded the formation of short-chain carboxylic acids like oxalic acid, acetic acid and formic acid, which were finally mineralized into $\mathrm{CO}_{2}$ and $\mathrm{H}_{2} \mathrm{O}$ as well as the formation of other inorganic ions like $\mathrm{NH}_{4}{ }^{+}, \mathrm{NO}_{3}{ }^{-}$and $\mathrm{NO}_{2}{ }^{-}$.

In general, LMWOAs are the end products of the degradation process of Fenton systems, such as acetic acid, which was difficult to be attacked by ${ }^{\circ} \mathrm{OH}$. Hence, LMWOAs are likely to be

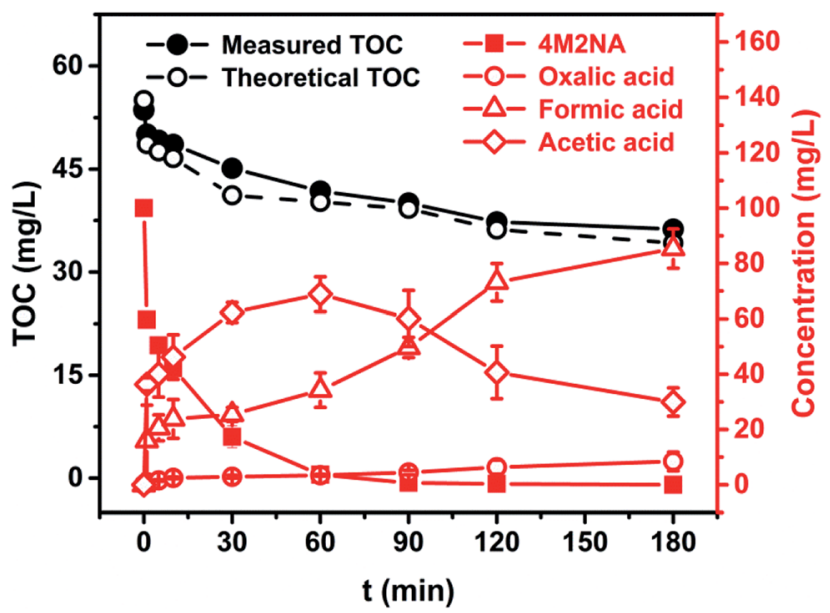

Fig. 7 Evolution of the major small molecular acid and measured and theoretical TOC. the major components of the remaining TOC in the system. ${ }^{59,63}$ The LMWOAs identified in this study mainly included oxalic acid, acetic acid and formic acid, and the variation of their concentrations with time were detected by HPLC method. Besides, to further confirm the major degradation pathway, the measured TOC at various time intervals during the degradation process of 4M2NA was compared with the theoretical TOC calculated by the actual concentration of 4M2NA, oxalic acid, acetic acid and formic acid, as shown in Fig. 7.

The concentration of acetic acid increased rapidly with reaction time from 1 to $60 \mathrm{~min}$, and reached a peak value of $68.88 \mathrm{mg} \mathrm{L}^{-1}$ at $60 \mathrm{~min}$. Then, as the reaction continued, the concentration of acetic acid decreased gradually. After $120 \mathrm{~min}$, the decrease rate slowed down, and the concentration dropped to $29.95 \mathrm{mg} \mathrm{L}^{-1}$ at $180 \mathrm{~min}$. The concentration of oxalic acid increased gradually with the reaction proceeding and remained at about $8.42 \mathrm{mg} \mathrm{L}^{-1}$ at the later stage of the reaction. Oxalic acid and iron ions could form quite stable organic complexes, which were not susceptible to degradation attacked by free radical. ${ }^{59}$ The concentration of formic acid showed a gradually increasing trend, and the final concentration was about $85.37 \mathrm{mg} \mathrm{L}^{-1}$ at $180 \mathrm{~min}$. On the other hand, it was clear that the theoretical TOC was nearly $94.41-97.11 \%$ of the measured TOC, which indicated that the oxalic acid, acetic acid and formic acid were the main end products and the pathway marked by red box was the major degradation way. These results provide significant information to deep understand the degradation mechanism of 4M2NA.

Besides, $\mathrm{NH}_{4}{ }^{+}, \mathrm{NO}_{3}{ }^{-}$and trace amounts of $\mathrm{NO}_{2}{ }^{-}$were detected at concentrations of $44.78,12.71$ and $0.36 \mathrm{mg} \mathrm{L}^{-1}$ respectively at the end of the reaction, which indicated that the 
removal of $-\mathrm{NO}_{2}$ and $-\mathrm{NH}_{2}$ by ${ }^{\circ} \mathrm{OH}$ during Fenton oxidation process was partly mediated by ionization.

\section{Conclusions}

The present study showed Fenton oxidation was highly effective to decompose $4 \mathrm{M} 2 \mathrm{NA}$ at a near neutral aqueous solution. The results were summarized as follows.

(1). The effect of initial $\mathrm{pH}, \mathrm{Fe}^{2+}$ and $\mathrm{H}_{2} \mathrm{O}_{2}$ concentrations on 4M2NA degradation efficiency was investigated. The initial concentrations of both $\mathrm{H}_{2} \mathrm{O}_{2}$ and $\mathrm{Fe}^{2+}$ affected the oxidation efficiency of $4 \mathrm{M} 2 \mathrm{NA}$, in which the $\mathrm{Fe}^{2+}$ had a more significant impact.

(2). The removal efficiency of 4M2NA (100 mg L $\left.{ }^{-1}\right)$ could reach $100 \%$ after $180 \mathrm{~min}$ at the condition of that the initial $\mathrm{pH}$ was $6.12 \pm 0.01$ and the initial $\mathrm{H}_{2} \mathrm{O}_{2}$ and $\mathrm{Fe}^{2+}$ concentrations were 4.0 and $0.4 \mathrm{mM}$ respectively. But the TOC removal efficiency was less than $32 \%$, which suggested that many byproducts recalcitrant to the Fenton oxidation were still present in the system.

(3). A total of nineteen reaction intermediates were identified by UV-Vis spectra analysis based on Gauss peak fitting, HPLC analysis combined with two-dimensional correlation spectroscopy and GC-MS detection, and two possible degradation ways were illustrated. Theoretical TOC calculated based on the concentration of oxalic acid, acetic acid, formic acid, and 4M2NA during the degradation process was nearly 94.41$97.11 \%$ of the measured TOC, which indicated that the oxalic acid, acetic acid and formic acid were the main products.

(4). The predominant mechanism and pathway of oxidative degradation of 4M2NA by Fenton method was preliminarily determined. With the attack of ${ }^{\circ} \mathrm{OH}, 4 \mathrm{M} 2 \mathrm{NA}$ was rapidly oxidized to 4-methoxy-2-nitrophenol, 4-methoxy-1,2-benzenediol and toluene successively. Then a large amount of oxalic acid, acetic acid and formic acid were produced after the benzene ring was opened. Eventually some of them could be mineralized to $\mathrm{CO}_{2}$, $\mathrm{H}_{2} \mathrm{O}, \mathrm{NH}_{4}{ }^{+}, \mathrm{NO}_{3}{ }^{-}$and trace amounts of $\mathrm{NO}_{2}{ }^{-}$.

These results may provide a significant insight to deep understand the degradation mechanism of 4M2NA during the Fenton oxidation process, which could provide theoretical basis and support for better treatment of 4M2NA contaminated surface and groundwater.

\section{Conflicts of interest}

There are no conflicts to declare.

\section{Acknowledgements}

This study was financially supported by the Fundamental Research Fund for the Central Universities (No. 2652017166), the fund of water quality control principles for safe storage of reclaimed groundwater (Project No. 51238001), the National Natural Science Foundation of China (Grant 41672239) and (Grant 41572229), the Research Fund of China Geological Survey (1212011121166 and DD20160300), and the National
Water Pollution Control and Treatment Science and Technology Major Project (2015ZX07406005-001).

\section{References}

1 L. Gu, N. Zhu, L. Wang, X. Bing and X. Chen, J. Hazard. Mater., 2011, 198, 232-240.

2 W. P. Ting, M. C. Lu and Y. H. Huang, J. Hazard. Mater., 2008, 156, 421-427.

3 G. Chen, K. Y. Cheng, M. P. Ginige and A. H. Kaksonen, Water Res., 2012, 46, 145-151.

4 A. El-Ghenymy, S. Garcia-Segura, R. M. Rodríguez, E. Brillas, M. S. El Begrani and B. A. Abdelouahid, J. Hazard. Mater., 2012, 221-222, 288-297.

5 N. Wang, Z. Tong, J. Jiang and W. Peng, Chem. Eng. J., 2015, 260, 386-392.

6 Y. Y. Lau, Y. S. Wong, S. A. Ong, L. N. Ho, K. Hussin and N. A. Lutpi, J. Taiwan Inst. Chem. Eng., 2017, 76, 27-34.

7 M. M. Rosli, P. S. Patil, H. K. Fun, I. A. Razak and S. M. Dharmaprakash, Acta Crystallogr., 2007, 63, 1039-1040.

8 N. Riaz, F. K. Chong, B. K. Dutta, Z. B. Man, M. S. Khan and E. Nurlaela, Chem. Eng. J., 2012, 185-186, 108-119.

9 A. L. Yang, G. H. Huang, X. S. Qin and Y. R. Fan, J. Hazard. Mater., 2012, 213-214, 421-433.

10 Y. Guo, Q. Xue, H. Zhang, N. Wang, S. Chang, H. Wang, H. Pang and H. Chen, RSC Adv., 2017, 8, 80-90.

11 L. Bai, Q. Qiao, Y. Yao, J. Guo and M. Xie, J. Cleaner Prod., 2014, 70, 4-14.

12 M. Dou, Q. Mi, C. Li and Y. Wang, Environ. Earth Sci., 2015, 74, 3681-3683.

13 P. Li, J. Wu, H. Qian, Y. Zhang, N. Yang, L. Jing and P. Yu, Exposure Health, 2016, 8, 331-348.

14 Y. S. C. Sarita, D. K. Tyagi and O. P. Yadav, Asian J. Res. Chem., 2012, 5, 1-7.

15 S. Datta, P. K. Bhattacharya and N. Verma, J. Membr. Sci., 2003, 226, 185-201.

16 W. Chai, X. Zhu, W. Liu, W. Zhang, Z. Zhou and Z. Ren, RSC Adv., 2016, 6, 6125-6132.

17 Y. Sun, D. Yin, J. Luo, Y. Xu and A. Li, Environ. Eng. Sci., 2016, $34,528-535$.

18 J. Y. Shen, H. Rui, H. X. Yu, L. J. Wang, J. F. Zhang, X. Y. Sun, J. S. Li, W. Q. Han and X. Lu, Bioresour. Technol., 2009, 100, 1922-1930.

19 H. Feng, Y. Wang, X. Zhang, D. Shen, N. Li, W. Chen, B. Huang, Y. Liang and Y. Zhou, Chem. Eng. J., 2016, 314, 232-239.

20 L. Gu, J. Y. Nie, N. W. Zhu, L. Wang, H. P. Yuan and Z. Shou, Chem. Eng. J., 2012, 189-190, 108-116.

21 J. Shen, C. Ou, Z. Zhou, J. Chen, K. Fang, X. Sun, J. Li, L. Zhou and L. Wang, J. Hazard. Mater., 2013, 260, 993-1000.

22 C. C. Hsueh, C. T. Chen, A. W. Hsu, C. C. Wu and B. Y. Chen, J. Taiwan Inst. Chem. Eng., 2017 , 79, 141-150.

23 Y. Ju, Y. Yu, X. Wang, M. Xiang, L. Li, D. Deng and D. D. Dionysiou, J. Hazard. Mater., 2016, 323, 611-620.

24 R. P. Cavalcante, R. S. L. Da, D. Bogo, A. M. Barbosa, M. E. Osugi, M. Blanco, S. C. de Oliveira, F. C. M. M. De, 
Amilcar Machulek Jr and V. S. Ferreira, Environ. Sci. Pollut. Res., 2013, 20, 2352-2361.

25 J. J. Pignatello, E. Oliveros and A. MacKay, Crit. Rev. Environ. Sci. Technol., 2006, 36, 1-84.

26 Y. Liu, X. He, Y. Fu and D. D. Dionysiou, Chem. Eng. J., 2016, 284, 1317-1327.

27 J. A. Khan, X. He, N. S. Shah, M. Sayed, H. M. Khan and D. D. Dionysiou, Chem. Eng. J., 2017, 325, 485-494.

28 K. Jaworek, M. Czaplicka and Ł. Bratek, Environ. Sci. Pollut. Res. Int., 2014, 21, 11917-11923.

29 V. N. Lima, C. S. D. Rodrigues and L. M. Madeira, Environ. Sci. Pollut. Res., 2017, 1-12.

30 A. El-Ghenymy, C. Arias, P. L. Cabot, F. Centellas, J. A. Garrido, R. M. Rodríguez and E. Brillas, Chemosphere, 2012, 87, 1126-1133.

31 N. Riaz, F. K. Chong, Z. B. Man, R. Sarwar, U. Farooq, A. Khan and M. S. Khan, $R S C A d v$., 2016, 6, 55650-55665.

32 N. Riaz, F. K. Chong, Z. B. Man, M. S. Khan and B. K. Dutta, Ind. Eng. Chem. Res., 2013, 52, 4491-4503.

33 M. R. D. Khaki, M. S. Shafeeyan, A. A. A. Raman and M. A. W. D. Wan, J. Environ. Manage., 2017, 198, 78-94.

34 X. R. Xu, H. B. Li, W. H. Wang and J. D. Gu, Chemosphere, 2004, 57, 595-600.

35 E. Neyens and J. Baeyens, J. Hazard. Mater., 2003, 98, 33-50.

36 M. M. Ballesteros Martín, J. A. Sánchez Pérez, J. L. Casas López, I. Oller and R. S. Malato, Water Res., 2009, 43, 653660.

37 J. A. Zimbron and K. F. Reardon, Water Res., 2005, 39, 865869.

38 C. K. Duesterberg and T. D. Waite, Environ. Sci. Technol., 2006, 40, 4189-4195.

39 N. Masomboon, C. Ratanatamskul and M. C. Lu, Environ. Sci. Technol., 2009, 43, 8629-8634.

40 N. Masomboon, C. Ratanatamskul and M. C. Lu, J. Hazard. Mater., 2010, 176, 92-98.

41 N. Masomboon, C. Ratanatamskul and M. C. Lu, Appl. Catal., A, 2010, 384, 128-135.

42 J. Shen, C. Ou, Z. Zhou, J. Chen, K. Fang, X. Sun, J. Li, L. Zhou and L. Wang, J. Hazard. Mater., 2013, 260, 993-1000.

43 C. Ravikumar and J. I. Hubert, Phys. Chem. Chem. Phys., 2010, 12, 9452-9460.
44 Y. Tsubokura, S. Aso, T. Koga, J. Kikuchi, T. Kobayashi, S. Hoshuyama, Y. Oshima, K. Miyata, Y. Kusune and T. Muroi, Drug Chem. Toxicol., 2015, 38, 361-374.

45 B. Gu, W. Ji, X. Q. Huang, P. S. Patil and S. M. Dharmaprakash, J. Appl. Phys., 2009, 106, 33511-33514. 46 T. X. H. Le, T. V. Nguyen, Z. A. Yacouba, L. Zoungrana, F. Avril, D. L. Nguyen, E. Petit, J. Mendret, V. Bonniol and M. Bechelany, Chemosphere, 2017, 172, 1-9.

47 S. Khan, X. He, J. A. Khan, H. M. Khan, D. L. Boccelli and D. D. Dionysiou, Chem. Eng. J., 2017, 318, 135-142.

48 H. Küpper, M. Spiller and F. C. Küpper, Anal. Biochem., 2000, 286, 247-256.

49 J. A. Yoon, Y. H. Kim, N. H. Kim, C. B. Moon, G. He and W. Y. Kim, J. Lumin., 2014, 153, 104-108.

50 I. Noda and Y. Ozaki, Practical Computation of TwoDimensional Correlation Spectra, John Wiley \& Sons, Ltd, ch. 3, 2005, pp. 39-46.

51 J. Zhang, L. Chen, H. Yin, S. Jin, F. Liu and H. Chen, Environ. Pollut., 2017, 225, 86-92.

52 J. A. Zimbron and K. F. Reardon, Water Res., 2009, 43, 18311840.

53 J. Yongsik, L. Wootaik, P. Jooyang and K. Younghun, Environ. Technol., 2009, 30, 183-190.

54 Y. Wu, S. Zhou, X. Ye, R. Zhao and D. Chen, Colloids Surf., A, 2011, 379, 151-156.

55 W. K. Yun and K. Y. Hwang, Water Res., 2000, 34, 2786-2790.

56 A. D. Bokare and W. Choi, J. Hazard. Mater., 2014, 275, 121135.

57 C. C. Su, L. M. Bellotindos, A. T. Chang and M. C. Lu, J. Taiwan Inst. Chem. Eng., 2013, 44, 310-316.

58 N. Klamerth, W. Gernjak, S. Malato, A. Agüera and B. Lendl, Water Res., 2009, 43, 441-449.

59 N. Zhu, L. Gu, H. Yuan, Z. Lou, L. Wang and X. Zhang, Water Res., 2012, 46, 3859-3867.

60 L. Fu, Z. Zhao, J. Ma and X. Hu, Catal. Commun., 2015, 65, 96-101.

61 P. R. Salgado, V. Melin, Y. Duran, H. D. Mansilla and D. Contreras, Environ. Sci. Technol., 2017, 51, 3687-3693.

62 Y. Liu, G. Zhang, S. Fang, S. Chong and J. Zhu, J. Environ. Manage., 2016, 182, 367-373.

63 G. Liu, H. Huang, R. Xie, Q. Feng, R. Fang, Y. Shu, Y. Zhan, X. Ye and C. Zhong, RSC Adv., 2016, 7, 71-76. 